Andrzej Piotrowski

Department of European Culture Research

Institute of Sociology

Faculty of Economics and Sociology

University of Lodz, Poland

\section{Fritz Schütze as a Significant Participant of the Sociological Milieu in Lodz}

DOI: https://doi.org/10.18778/1733-8077.10.1.13

$\mathrm{T}$

render a history of Fritz Schütze's cooperation with a group of sociologists working in the Institute of Sociology of the University of Lodz, one must start with the first contacts established with him by Marek Czyżewski, a member of that group, who was invited to an international conference on new approaches to interpretive sociology, organized by Fritz Schütze in Kassel in 1981. As a result of those contacts Fritz Schütze visited the Institute of Sociology in 1986 to give a series of lectures on his own approach to the biographical method in sociology. Those lectures, as I remember them, were focused, on the one hand, on ways of doing sociology based on a conceptual scheme of biographical processes as a theoretical perspective, and, on the other, they were combined with workshop-like demonstration of how that perspective can be applied to, and explored in, empirical research in a methodical way. The Polish participants, mostly members of the Department of Sociology of Culture, who were familiar with the tradition of biographical approach developed by Florian Znaniecki, and next - by Józef Chałasiński, Jan Szczepański, and Antonina Kłoskowska, the last one being the founder of the Department of Sociology of
Culture in Lodz, and who started in the second half of the 70s their studies on the newer directions in the interpretive sociology (e.g., symbolic interactionism, ethnomethodology, and phenomenological sociology), found those meetings as inspiring and seminal.

Since that time, the cooperation between that group of sociologists in Lodz, and Fritz Schütze and his co-workers - Gerhard Riemann, Lena Inowlocki, Bärbel Treichel, and Thomas Rheim in Kassel, and then also Anja Schröder-Wildhagen and Ulrike Nagel in Magdeburg, to mention only a few persons most deeply engaged in that network - has been intensified and developed in many forms. One of them is a frequent and regular participation of members of the Department of Sociology of Culture in both international conferences and workshops organized by Fritz Schütze and his collaborators, first in Kassel and then in Magdeburg. During one of our first seminars, we analyzed "Robert Rasmus" autobiographical account published in Studs Terkel's book The Good War, and we got familiar with an earlier version of the article by Fritz Schütze on this case and its sociological implications. The article is being published for the first time in this volume of QSR. It must be noted here, however, that his role in the enlarging of international contacts of his Polish colleagues was not confined to personal invitations addressed to them, as he often was taking a role of a liaison-person to promote and facilitate such contacts.

Another form of Fritz Schütze's ties with Lodz is his manifold contribution to a development of academic careers of a number of persons. On the one hand, Marek Czyżewski, after his visiting professorship in Kassel and then the habilitation scholarship and visiting professorship in Magdeburg, took his habilitation degree in Otto-von-Guericke-Universität in Magdeburg. Katarzyna Waniek, after regular PhD studies in Magdeburg, took her PhD degree there having Fritz Schütze as professor conferring that degree. On the other hand, the habilitation of Alicja Rokuszewska-Pawełek on chaos and pressure in World War II experiences of Poles, proceeded in Lodz and based on a theoretical framework taken from Fritz Schütze's writings, owed very much, as well, to her immediate and personal contacts with him. The same goes, with no doubt, in case of Kaja Kaźmierska's both PhD dissertation on the Polish World War II experiences and issues of ethnic and national identity in Poland's Eastern borderlands, and habilitation on relations between biography and memory studied in the context of Shoah survivors' biographical experiences. Finally, it may be noted that Andrzej Piotrowski's visiting professorship in Magdeburg was an initial point in establishing a regular academic program of the European Studies in the Institute of Sociology in Lodz after his coming back home, and it was Fritz Schütze who played a significant role in promoting that idea and giving a strong institutional support to it as a representative of the University of Magdeburg, where such a program was already established.

Still another form of the ties that link Lodz and Magdeburg is a series of workshops which have been designed by him to practice the interpretive sociology, orientated to the biographical approach, but equally open to various modalities of discourse analysis and sociosemiotic perspectives in general, so that to combine the educational and research work of students and their teachers/researchers in common endeavors. This idea, grounded in regular practices that have been already worked out by Fritz Schütze and his team in Kassel, has found its application in the context of international cooperation that took a shape, with time, of Tri-National Research Platform: European Identity Work, a workshop that was initially grouping researchers and students form Magdeburg, Bangor (Wales), and Lodz, and then, enlarged in its scope, also from Bamberg and Belfast. As there is no place here to document their history in detail, I will only note that anywhere from ten to twenty such workshops took place, that are continued with some breaks since 1997 till today, that they are credited with ECTS points as 30-hour long educational modules, that since, at least, 2005 they are open to students of sociology and the European Studies both in Lodz and in Magdeburg, and sometimes students of social work, and, finally, that since 2011 they have come to form an integral part of activities within the frame of larger research projects (grants) in the universities engaged in that cooperation. The workshop organized in Magdeburg in 2011 was closely linked with the FP7 project "EUROIDENTITIES. The Evolution 
of European Identity: Using biographical methods to study the development of European Identity" (carried out in Lodz by Andrzej Piotrowski as a scientist-in-charge for the Polish team, Kaja Kaźmierska, and Katarzyna Waniek), and the workshop in 2013 was connected with a Polish-German project of study (since 2012, led in Poland by Kaja Kaźmierska) on "The People's Republic of Poland and the German Democratic Republic in memory and biographical experiences of people born between 1945-55. Sociological comparison based on biographical comparison," carried out in close collaboration of Lodz and Magdeburg.

Finally, it is just the collaboration in the large research projects that forms strong bonds between the sociologists working in Lodz and Fritz Schütze. Two of them have been already mentioned. One may add another and much earlier one (19921994), initially planned to carry out together, but eventually limited, for many organizational reasons, to the Polish context, namely, the project on biographical dimensions of the war experiences during World War II, in which Fritz Schütze's theoretical and methodological perspectives both were playing a decisive role. Results of that project, which was headed by Zbigniew Bokszański, have been published in Biography and the National Identity, a book edited by Marek Czyżewski, Andrzej Piotrowski, and Alicja Rokuszewska-Pawełek. The idea of this project was the result of discussions and shared interests in World War II. An earlier out- come of these discussions was the analysis of autobiography of Rudolf Höss, the commandant of KL Auschwitz. Marek Czyżewski and Alicja Rokuszewska-Pawełek's larger study on this autobiography can be considered as the first analysis based on Fritz Schütze's approach published in Polish (Czyżewski M., Rokuszewska-Pawełek A., 1989/90, “Analiza autobiografii Rudolpha Hössa," Kultura i Społeczeństwo, Vol. 33, No. 2 and 3/4 and Vol. 34, No. 1). One must also point another, earlier large project within the frame of the Leonardo da Vinci program (20032006), “INVITE. New Ways of Biographical Counselling in Rehabilitative Vocational Training," where Fritz Schütze cooperated with the members of the Department of General Sociology (with Agnieszka Golczyńska-Grondas as a scientist-in-charge in Lodz) and practitioners working in Lodz in the field of social work and related domains.

For all his merits, he was awarded by the University of Lodz in 2005, just in time for its $60^{\text {th }}$ anniversary, a medal Universitatis Lodziensis Amico. Amicus is indeed a good term here. It renders much more than an academic cooperation in its formal sense. Yet, looking for another category that seems to be apt to render Fritz Schütze's ties with a number of sociologists who work in Lodz, I propose using also the term significant participant. Both of the terms, put together, are adequate to his unusual ability to integrate all virtues of tactful and respectful intellectual mastership with a climate of genuine, non-perfunctory friendship.

\footnotetext{
Piotrowski, Andrzej. 2014. "Fritz Schütze as a Significant Participant of the Sociological Milieu in Lodz" Qualitative Sociology Review 10(1):364-366. Retrieved Month, Year (http://www.qualitativesociologyreview.org/ENG/archive_ eng.php).
} 